\title{
Domestic Violence in the Homes of College Students, New Providence, The Bahamas
}

\author{
Susan J. Plumridge ${ }^{1}$ \\ William J. Fielding \\ The College of The Bahamas
}

\begin{abstract}
This paper identifies the link between a number of undesirable behaviours and domestic violence in 588 households of college students in Nassau, The Bahamas. The survey indicates that about $21 \%$ of college students could be living in homes with domestic violence. Further, domestic violence is associated with other deviant behaviours which may have adverse affects on household members and ultimately the welfare of the nation. The findings suggest that government policy regarding alcohol could be changed to reduce the participation of residents in behaviours linked to domestic violence.
\end{abstract}

\section{INTRODUCTION}

In the Caribbean and The Bahamas, crime is of ever-increasing concern (United Nations Office on Drugs and Crime \& World Bank, 2007) and the 2010 censuses in the region will, for the first time, include specific questions on crime (C. Mackey, personal communication, 2008). In 2007, an opinion poll conducted in The Bahamas by The Nature Conservancy and the Bahamas National Trust reported that $74 \%$ of voters considered crime to be an "extremely serious" issue. The concern regarding violence is magnified by the importance of tourism to the Caribbean and the need for the region to appear safe if it is to attract tourists. However, crimes against tourists centre on robbery and petty crime whereas crime against residents focuses on victimisation (de Albuquerque \& McElroy, 1999). One important aspect of victimization is domestic violence. In The Bahamas, actions which contribute to domestic violence are hitting, slapping, pushing, swearing, hurting, threatening, denying freedom and withholding money (Bahamas Crisis Centre, n.d.).

Awareness of the social impact of domestic violence in The Bahamas resulted in a women's crisis centre being opened in 1982 to shelter battered women, but in recent years the shelter has widened its scope to include men (Gibson, 2002). The far-reaching effects of domestic violence were felt in Nassau in 2001. The "world famous" straw market (Smith, 2001) was allegedly destroyed by a fire resulting from a domestic dispute

\footnotetext{
${ }^{1}$ Susan J. Plumridge, School of Social Sciences and William J. Fielding, Director of Planning, The College of The Bahamas. Professor Plumridge is deceased.

E-mail: wfielding@cob.edu.bs

Acknowledgments: We are grateful to Terry Fountain for access to the Ministry of Health study data on child health in The Bahamas, the Research and Planning Department of the Royal Bahamas Police Force and the Department of Social Services for sharing their data. We are also grateful to the Department of Statistics for generating customised tables from the 2000 census. The HITS Index@ was used with permission of Kevin Sherin. The data were collected by members of the Spring 2008 class of SOS 200 as part of their course work.

How to cite this article in APA (7th ed. Style): Plumridge, S. J., \& Fielding, W. J. (2009). Domestic violence in the homes of college students, New Providence, The Bahamas. The College of The Bahamas Research Journal, 15; 4555. https://doi.org/10.15362/ijbs.v15i0.116
}

(C). J. Plumridge \& W. J. Fielding, 2009. Journal compilation (c) The College of The Bahamas Research Journal, 2009 
between a market vendor and the arsonist. Merzer and White (2001) reported that the fire was "started by a jealous lover who tossed a fire bomb at a stall operated by his former girlfriend” (p. A1).

From 1996 to 2007, the number of homicides attributed to domestic violence has been increasing (Figure 1), with a high of 17 domestic-related homicides in 2007 (Royal Bahamas Police Force, Research \& Planning Unit, 2008a). The Bahamian media gives the impression that domestic violence is on the rise and such reports and editorials probably reflect the increasing concern with which society views domestic violence ("Women and domestic violence”, 2006).

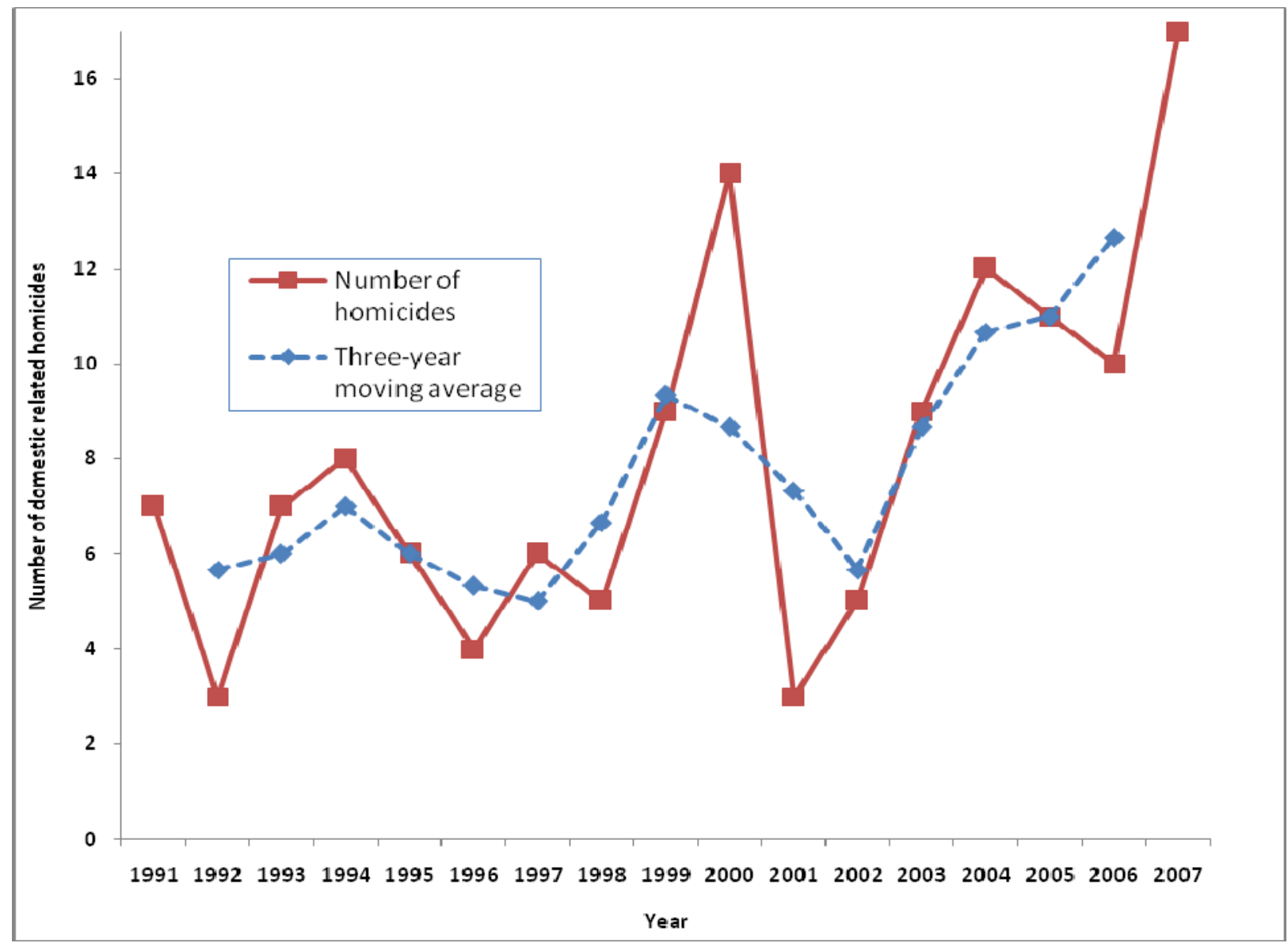

Figure 1: Number of homicides attributed to domestic violence in The Bahamas, 1991-2007. Adapted from unpublished raw data on homicides in The Bahamas provided by the Royal Bahamas Police Force, Research \& Planning Unit. Used with permission.

Currently, there appear to be no official statistics on domestic violence in The Bahamas (S. Collie, personal communication, 2008); however, the Bahamas Department of Social Services (2008, 2009) has reported increasing numbers of child abuse cases since 1990. Sexual abuse (including incest), physical abuse and verbal emotional abuse of children have all increased (see Figure 2). These recent higher figures may represent real increases in abuse or may result from better reporting of cases, or both. In 2008, the Bahamas government declared the month of April to be "National Child Protection Month" in an effort to highlight child abuse and domestic violence issues (Bahamas 
Government, 2008). The universal nature of domestic violence means that it has been researched worldwide (for example, Jeyaseelan, Sadowski, Kumar, Hassan, Ramiro, \& Vizcarra, 2004) and has received attention from international agencies such as the United National Children's Fund (2000).
A report published by the World Health Organization (Garcia-Moreno, Jansen, Ellsberg, Heise, \& Watts, 2005) stated that domestic violence “...continues to be frighteningly common and to be accepted as 'normal' within too many societies” (p. vii).

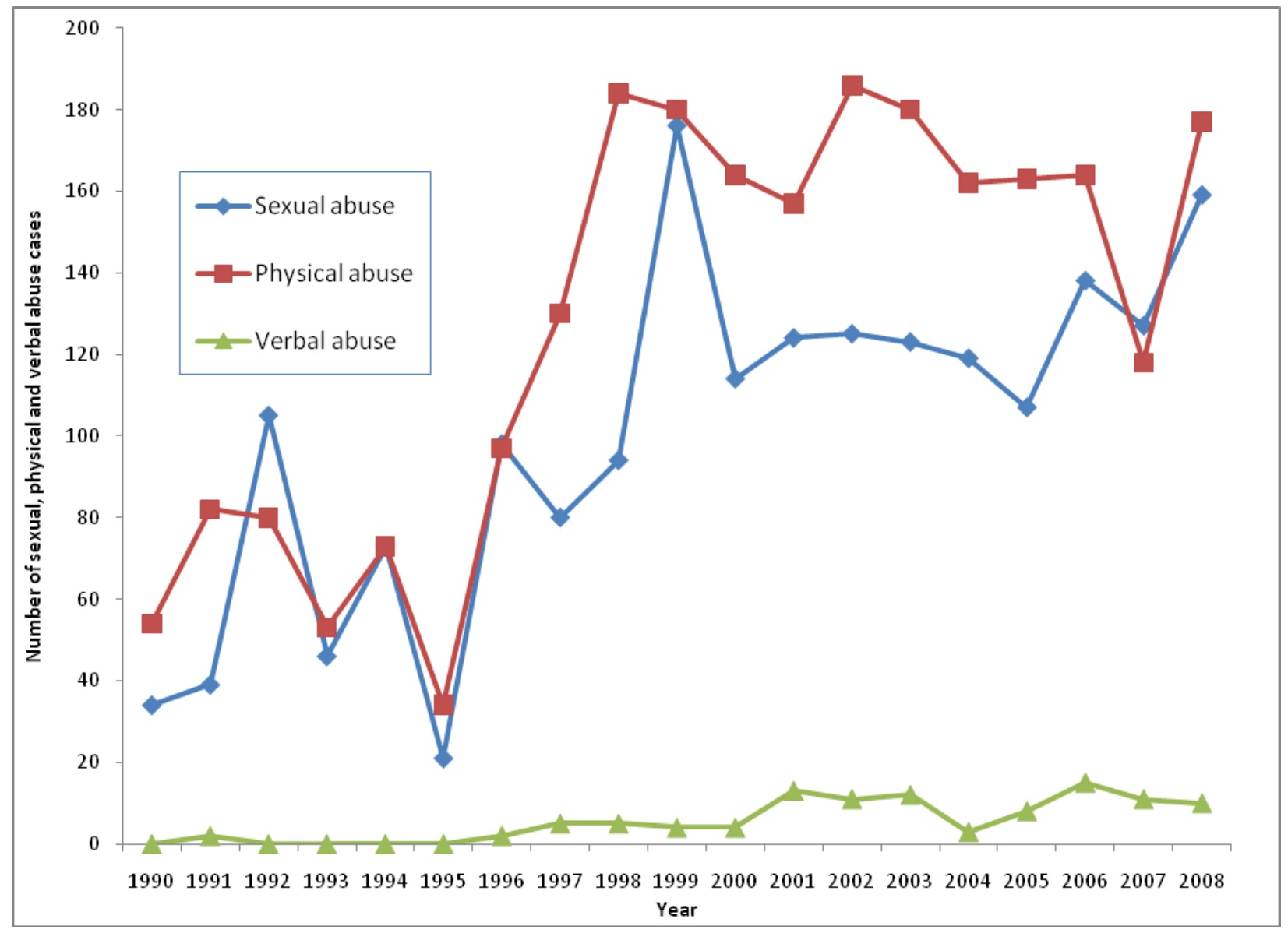

Figure 2: Number of reported cases of selected types of child abuse in New Providence, The Bahamas, 1990-2008. "Sexual abuse" includes incest. Adapted from unpublished raw data provided by The Bahamas Department of Social Services. Used with permission.

A 1998 study of child health by the Bahamas Ministry of Health's, Health Information Unit (2001) indicated the presence of elements of domestic violence in Bahamian homes. Responses from 1,007 children (mean age: 13.9 years, SE: 0.06 ) indicated that $25.3 \%$ worried about violence in the home, $22.2 \%$ had been physically abused, $12.9 \%$ had been sexually abused, $35.8 \%$ had suffered emotional or verbal abuse and additionally $21.8 \%$ worried about their parents' drinking or drug use. These concerns over parental alcoholism and drug abuse may be based in reality as suggested by Novak (1999) “...parental alcoholism and drug abuse threaten the stability of families" in The Bahamas (p. 120). These figures also suggest that children can grow up exposed to domestic 
violence and so they may learn behaviours which they may practice in later life. Consequently, as Kellert and Felthous (1985) have pointed out, the upbringing of children in The Bahamas may be influenced by domestic violence.

Research by Fielding, Mather and Isaacs (2005) found that pets are found in many homes in The Bahamas and may even be considered members of the family, and as such, violence towards them can also considered violence towards a household member (Humane Society of the United States, 2009). Hitting pets to discipline them is not uncommon in the Caribbean (Alie, Davis, Fielding \& Maldonado, 2007), and it is possible that this behaviour, if learnt at a young age by household members, may be carried on into adulthood and be transferred to humans. The experiences of officers of the Bahamas Humane Society show that children who abuse animals can become engaged in criminal activities in adulthood (Rolle, 2009). These observations suggest a number of areas for further research within the Bahamian community with regard to learned behaviours towards pets and how the treatment of animals in childhood can influence the treatment of humans in adulthood; such linkages have been explored by Ascione (2008) and others.

This paper examines the association between domestic violence and selected behaviours in New Providence. We use data from a previous study designed to investigate the link between animal abuse and domestic violence (Fielding \& Plumridge, in press) to look at the prevalence of deviant behaviours in homes of college students with and without domestic violence. Identification of the linkages, if any, can assist social workers in identifying homes which may be at higher risk of suffering from the trauma of domestic violence. Further, they may suggest changes to government policy which, in its current form, may inadvertently fuel domestic violence.

\section{METHOD}

Domestic violence can take many forms (Krauss, 2006) and a number of tools have been used to measure domestic violence (Dwyer, 1999). The HITS $\odot$ inventory developed by Sherin, Sinacore, Li, Zitter and Shakil (1998) was used to classify whether the respondent had been subjected to domestic violence and if domestic violence was present in the respondent's household. The HITS $\mathbb{C}$ inventory asks four questions relating to hitting, intimidating, threatening and swearing, and so includes the features of domestic violence listed by the Bahamas Crisis Centre on their website.

Questions on substance abuse were included, as this can be linked to domestic violence (Bhatt, 1998), along with the presence of a person with a criminal record living in the household, as prior convictions can increase the risk of domestic violence (Fukurode, 2005). The survey asked questions concerning sexual abuse and attitudes towards living in the household. Respondents were asked to give answers which related only to their present household. Questions relating to who was responsible for the behaviour or who was the victim of the behaviour sometimes resulted in ambiguous information, such as "everyone" or "cousin", so the results presented relate only to the sex of the individuals who could be identified.

The target population consisted of college students aged 18 or over. With the permission of the instructor, students visited classes, explained the nature of the study and requested the participation of students. Each respondent was assumed to represent a different household. Participants signed a consent form which stated the voluntary nature of the study and its aims; they were also informed that if they were distressed by the questions, college counsellors were available to assist them. Confidentiality of the data was stressed to all participants, both 
orally and in writing, and the study was undertaken with the endorsement of the College of The Bahamas' Office of Research, Graduate Programmes \& International Relations.

\section{RESULTS}

A total of 641 students participated, although not all the questionnaires were completed. Only 612 respondents completed the questions which allowed homes to be classified by the presence or absence of domestic violence. Some students were living in student accommodation or elsewhere, so only the replies of 588 students who were currently living in their parents' homes (70.7\%), their own home $(16.0 \%)$ or in the home of some other relative $(12.8 \%)$, were retained for analysis of household-related questions. Most of the students were under 21 years (64.3\% of 585 replies), and $70.3 \%$ (of 586 replies) were female. Domestic violence was detected in $21.3 \%$ of households.

The data in Table 1 show that the presence of domestic violence was associated with elevated risks (Odds ratios) of deviant behaviours, including sexual abuse of household members and the intentional harming of pets. Respondents perceived homes with domestic violence as being undesirable places in which to live (See responses to "Respondent considers the home to be loving" and "Respondent would leave the household if they could”).

Table 1

The association between domestic violence in the home and activities/perceptions of household members as reported by college students.

\begin{tabular}{|c|c|c|c|c|c|}
\hline \multirow[b]{2}{*}{ Item } & \multicolumn{2}{|c|}{$\begin{array}{c}\text { Domestic } \\
\text { violence in the } \\
\text { home }\end{array}$} & \multirow[b]{2}{*}{ Fisher's exact test* } & \multirow{2}{*}{$\begin{array}{l}\text { Odds ratio, } \\
\text { compared to } \\
\text { domestic } \\
\text { violence }\end{array}$} & \multirow[t]{2}{*}{$\begin{array}{c}95 \% \\
\text { confidence } \\
\text { limits }\end{array}$} \\
\hline & Yes & No & & & \\
\hline Pets well cared for & $83.9 \%$ & $95.3 \%$ & $p=0.007, n=267$ & 0.26 & $0.10-0.68$ \\
\hline Pets hit to train them & $71.2 \%$ & $56.1 \%$ & $p=0.057, n=248$ & 1.93 & $0.99-3.74$ \\
\hline Respondent considers the home to be "loving" & $65.3 \%$ & $90.9 \%$ & $p<0.001, n=573$ & 0.19 & $0.11-0.31$ \\
\hline $\begin{array}{l}\text { Respondent would leave the household if they } \\
\text { could }\end{array}$ & $48.7 \%$ & $20.7 \%$ & $p<0.001, n=564$ & 3.64 & $2.38-5.59$ \\
\hline Pets intentionally harmed & $45.6 \%$ & $13.3 \%$ & $p<0.001, n=275$ & 5.57 & $2.85-10.49$ \\
\hline Alcohol used in excess by a household member & $29.2 \%$ & $15.5 \%$ & $p=0.001, n=576$ & 2.23 & $1.39-3.57$ \\
\hline Respondent is a victim of domestic violence & $21.8 \%$ & $4.9 \%$ & $p<0.001, n=298$ & 5.37 & $2.26-12.74$ \\
\hline Illegal drugs used by a household member & $18.3 \%$ & $8.1 \%$ & $p=0.002, n=578$ & 2.55 & $1.44-4.52$ \\
\hline Any one sexually abused in the household & $14.0 \%$ & $4.3 \%$ & $p<0.001, n=568$ & 3.68 & $1.85-7.33$ \\
\hline Household member with criminal record* & $13.4 \%$ & $3.8 \%$ & $\begin{array}{c}p<0.001, n=572 \\
d f=2\end{array}$ & 3.98 & $1.95-8.15$ \\
\hline
\end{tabular}

Note: * A Chi-squared test was used to allow for a third option "Do not know". 
The sex of the persons caught up in the behaviours investigated is given in Table 2 . The relationships between these persons and the respondent were apparently complex and sometimes unclear, so only the sex of clearly reported persons is presented. Some respondents indicated that the hitting, insulting, threatening and swearing was done by "everyone" in the home and some qualified this, "it's not taken seriously", "all in fun” or "it’s done for jokes". Males were more likely than females to be involved in most of the behaviours listed in Table 2. However, while females were more likely to have been sexually abused, males were also victims. Males and females were almost equally likely to be responsible for the hitting, insulting, threatening and swearing.

\section{Table 2}

Sex of person(s) associated with selected behaviours in households as reported by college students.

\begin{tabular}{lcc}
\hline Item & Males & $\begin{array}{c}\text { No of responses } \\
\text { indicating sex }\end{array}$ \\
\hline Who uses illegal drugs in the household & $83.0 \%$ & 46 \\
Who has a criminal record & $82.8 \%$ & 30 \\
Who uses alcohol in excess in the household & $80.3 \%$ & 99 \\
Who is responsible for hitting, insulting, threatening \& screaming in the home & $49.6 \%$ & 358 \\
Who is the victim of the hitting, insulting, threatening \& screaming in the home & $39.5 \%$ & 357 \\
Who is/was sexually abused in the household & $29.7 \%$ & 30
\end{tabular}

\section{DISCUSSION}

While the results from this study were predictable based upon the literature (Ascione, 2008), they do confirm linkages between the behaviours found in other communities and those in New Providence. Although the results apply only to the college student population, where triangulation is possible with the Ministry of Health study (2001), the figures appear to be broadly similar. The level of domestic violence found in this study is in line with that found elsewhere in the Caribbean. However, it should be noted that the studies have used different target groups so a range of values should be expected and comparisons are not easy. Barbados, a country with many similarities to The Bahamas, reported that $30 \%$ of women (20-45 years) had been harmed due to domestic violence (Creel, 2001), a higher figure than found in this study, which probably reflects the older age group investigated in Barbados.

Some respondents who were victims of domestic violence did not seem to acknowledge that domestic violence was in their homes (Table 1). We could conjecture that this was because the behaviours of hitting, insulting, threatening and swearing are not really identified as domestic violence unless they are directed against an individual and so may be regarded as "normal" behaviours. As some respondents pointed out, such behaviours were not "taken seriously" or were "all in fun" and that "everyone" in the home participated. Further research would be useful to investigate attitudes to hitting, insulting, threatening and swearing between household members.

The correlation between alcohol abuse and domestic violence has also been observed in 
studies elsewhere (Jeyaseelan et al., 2004). In The Bahamas alcohol abuse in homes with domestic violence was over twice as likely as in homes without domestic violence (Odds ratio 2.23, 95\% confidence limits 1.4-3.6). Does alcohol abuse cause domestic violence? While there is no clear answer to this question, the link does exist (Hanson, 2007) and it should be remembered that in The Bahamas alcohol is "duty-free" to both tourists and residents ${ }^{2}$. Given the link between alcohol and domestic violence it may be relevant to query why alcohol is available to residents duty-free. The price of alcohol may account for the fact that The Bahamas has one of the higher consumption rates per capita of alcohol (10.4 litres), placing it $20^{\text {th }}$ out of 181 countries (World Health Organization, 2008) and as far back as 1972, Spencer cited it as the "number one health problem" (p. 112) which points to the longstanding nature of its use/abuse. Alcohol consumption and its effects have been a cause of concern in The Bahamas which appears to have been primarily directed towards the health effects on the drinker (Archer, 2003), rather than the wider implications of alcohol abuse-which can include domestic violence. Although studies such as that by Kenkel (1996) have shown that increasing the price of alcohol does not affect the consumption of alcohol uniformly across all types of drinker, increasing the price of alcohol could reduce its consumption and so might be a useful policy lever to reduce domestic violence. However, appropriate legislation and its enforcement may be even more effective in reducing alcohol consumption (Kenkel, 1996). The link between alcohol abuse and violence in The Bahamas would appear to make this an important area for further research.

\footnotetext{
${ }^{2}$ Note that alcohol in The Bahamas is only subjected to a stamp tax, there is no customs duty or consumption tax such as a value added tax levied. (Rolle \& Gibson, 2009). In the United Kingdom, alcohol is subjected to two taxes (Institute of Alcohol Studies, 2008).
}

Those participants who reported the use of illegal drugs in their households indicate the limits of the success of the authorities in enforcing the law. This is despite the police charging 3,876 people with illegal drug offences between 2005-2007 (Royal Bahamas Police Force, Research \& Planning Unit, 2008b). Clearly, there is a need to continue enforcing the laws concerning illegal drugs, particularly in light of the association between their use and violence. As has been suggested by Smart and Patterson (1990), education of residents to increase their awareness of the multifaceted issues associated with drug abuse may be beneficial.

The presence of an ex-convict in a household is linked with an increase in the risk of domestic violence. Fukurode (2005) found that domestic murder has been the end point of domestic violence in troubled relationships, and given the fact that many murders in The Bahamas are a result of domestic violence this finding is cause for concern. These observations point to the need to monitor exconvicts and to ensure that household members are aware of the risks of having exconvicts in their homes. In the Bahamian context, it should be noted that persons on bail, sometimes for homicide, can re-offend and even kill again (Hanna, 2005), so this highlights the need for a legal system to protect society by the appropriate restraint of suspects.

Overall, it would appear that households with domestic violence are not perceived to be places where respondents would wish to stay (if they had the option to leave) and are not considered to be "loving"; in other words they may not be considered places in which respondents would choose to live. It would be of interest to know why those respondents who lived in homes with domestic violence did not always wish to leave.

Animals also suffer as result of domestic violence. They are at greater risk of being 
intentionally harmed and neglected (or not well cared for). Clearly, once the abuse of pets or domestic violence is identified, a cross-reporting protocol needs to be activated so that social services and animal welfare groups can share information so that both humans and animals can be protected from further harm (Long, Long \& Kulkarni, 2007). As has been noted by Lockwood and Hodge (1986) "animal abuse is not just the result of a personality flaw in the abuser, but is often symptomatic of a deeply disturbed family" (p. 2) and so is a link which should be taken seriously. Simmons and Lehmann (2007) noted that when the person who perpetuates domestic violence also harms pets they are likely to be "dangerous" individuals (p. 1218). These connections indicate that Bahamian society needs to be aware of the "tangled web" of deviant household behaviours and appreciate that it also includes intentional harm (Lockwood \& Hodge, 1986) and neglect of pets (Fielding, 2009).

Thompson and Gullone (2003) found that merely by witnessing violence, children are at a higher risk of becoming abusers in later life and research by Rivett and Kelly (2006) indicates that there is "psychological evidence that children are affected by witnessing domestic violence” (p. 225). Consequently, there are potential long-term harmful effects on children who witness, let alone become victims of, violence towards pets or people. These insidious consequences of the behaviours studied here make it important that society, including neighbours, government and non-governmental agencies, work together to minimise both the short and long-term suffering which may occur if these behaviours are not swiftly curtailed or monitored.

Females and males were almost equally responsible for the hitting, insulting, threatening and swearing in the household. One hypothesis could be that economic strains within households with children may correlate with the composition of the household. In the 2000 Bahamas census, of 43,297 households with children, 14,117 (32.6\%) were headed by single females and 7,471 (17.3\%) were headed by females who had never married. The income of households headed by never-married females was $\$ 27,123$, as opposed to $\$ 30,558$ for households headed by single females, \$37,495 for households headed by single males, $\$ 40,928$ for households headed by married females and \$46,581 for households headed by married males (Bahamas. Department of Statistics, 2008). These differences in household income and the participation of certain females in hitting, insulting, threatening and swearing behaviour could reflect the economic difficulties faced by these heads of households, and this struggle could then be manifested by violent behaviour towards vulnerable members of the household. Further research is clearly required to better understand who is responsible for behaviours of concern in households and why.

This descriptive study again linked domestic violence with undesirable behaviours and demonstrates that domestic violence is one of several possibly harmful behaviours which “co-occur” (McPhedran, 2009, p. 41). Further research is required to examine the underlying causes of domestic violence in the community and to assess the effectiveness of social interventions and government policy to protect all household members from violence. 


\section{REFERENCES}

Alie, K., Davis, B. W., Fielding, W. J., \& Maldonado, F. G. (2007). Attitudes towards dogs and other "pets" in Roseau, Dominica. Anthrozoös, 20(2), 143-154. doi: 10.2752/175303707X207936

Archer, C. (2003). Bahamian alcoholism, 19552003, \& other drug abuse, 1968-2003: A works compilation. Nassau: Colmar.

Ascione, F. R. (Ed.). (2008). The international handbook on animal abuse and cruelty. Theory, research, and application. West Lafayette, IN: Purdue University Press.

Bahamas Crisis Centre (n.d.). Domestic violence. Retrieved from http://www.bahamascrisiscentre.org/page5.html

Bahamas. Department of Social Services. (2008). [Child abuse statistics, 1990-2007]. Unpublished raw data.

Bahamas. Department of Social Services. (2009). [Child abuse statistics, 2008]. Unpublished raw data.

Bahamas. Department of Statistics. (2008). [Household income by head of household classed by marital status in homes with children, from 2000 census]. Unpublished raw data.

Bahamas. Government. (2008). Child protection month 2008. Retrieved from http://www.bahmas.fov.bs/childprotection

Bahamas. Ministry of Health, Health Information Unit. (2001). [Bahamas youth health survey]. Unpublished raw data.

Bhatt, R. V. (1998). Domestic violence and substance abuse. International Journal of Gynaecology \& Obstetrics, 63, Suppl. 1, S35S31.

Creel, L. (with Lovera, S., \& Ruiz, M.). (2001). Domestic violence: An ongoing threat to women in Latin America and the Caribbean. Retrieved from Population Reference Bureau website: http://www.prb.org/Articles/2001/DomesticVio lenceAnOngoingThreattoWomeninLatinAmeric aandtheCaribbean.aspx de Albuquerque, K., \& McElroy, J. (1999).

Tourism and crime in the Caribbean. Annals of Tourism Research, 26(4), 968-984.

Dwyer, D. (1999). Measuring domestic violence: an assessment of frequently used tools. Journal of Offender Rehabilitation, 29(1/2), 29-33.

Fielding, W. J. (2009). Affects of domestic violence on dog care and human-animal interactions as reported in New Providence, The Bahamas. Manuscript submitted for publication.

Fielding, W. J., \& Plumridge, S. (in press). The association between pet care and deviant household behaviours in an Afro-Caribbean, college student community in New Providence, The Bahamas. Anthrozoos.

Fielding, W. J., Mather, J., \& Issacs, M. (2005). Potcakes: Dog ownership in New Providence, the Bahamas. West Lafayette, IN: Purdue University Press.

Fukurode, M. L. (2005). Murder at home: An examination of legal and community responses to intimate femicide in California. Los Angeles: California Women's Law Center. Retrieved from http://www.cwlc.org/files/docs/ MurderAtHome_FULL_REPORT.pdf

Garcia-Moreno, C., Jansen, H. A. F. M., Ellsberg, M., Heise, L., \& Watts, C. (2005). WHO multicountry study on women's health and domestic violence against women: Initial results on prevalence, health outcomes and women's responses. Geneva: World Health Organization. Retrieved from http://www.who.int/gender/violence/who_multi country_study/en/

Gibson, S. (2002, March 6). The Crisis Centre celebrates its 20th anniversary. Nassau Guardian. Retrieved from http://archive.nassauguardian.net

Hanna, C. (2005). Homicide in The Bahamas 1991-2003: A descriptive research study. Nassau: Royal Bahamas Police Force.

Hanson, D. J. (2007). Drinking alcohol and domestic abuse. Retrieved from Alcohol Problems and Solutions website: http://www2.potsdam.edu/hansondj/controversi es/1090863351.html 
Humane Society of the United States (2009). Animal cruelty and family violence: Making the connection. Retrieved from

http://www.hsus.org/hsus_field/first_strike_the _connection_between_animal_cruelty_and_hu man_violence/animal_cruelty_and_family_viol ence_making_the_connection/

Institute of Alcohol Studies (2008). Alcohol: Tax, price and public health. Retrieved from http:// www.ias.org.uk/resources/factsheets/tax.pdf

Jeyaseelan, L., Sadowski, L. S., Kumar, S., Hassan, F., Ramiro, L., \& Vizcarra, B. (2004). World studies of abuse in the family environment: Risk factors for physical intimate partner violence. Injury Control and Safety Promotion, 11(2), 117-124.

Kellert, S. R., \& Felthous, A. R. (1985). Childhood cruelty towards animals among criminals and noncriminals. Human Relations, 38, 1113-1129. doi: 10.1177/001872678503801202

Kenkel, D. D. (1996). New estimates of the optimal tax on alcohol. Economic Inquiry, 34, 296-319.

Krauss, H. H. (2006). Perspectives on violence. Annual of the New York Academy of Sciences, 1087, 4-21. doi: 10.1196/annals.1385.020

Lockwood, R., \& Hodge, G. R. (1986). The tangled web of animal abuse: The link between cruelty to animals and human violence. (NCJ 155688) [Abstract]. Retrieved from National Criminal Justice Reference Service Abstracts database.

Long, D. D., Long, J. H., \& Kulkarni, S. J. (2007). Interpersonal violence and animals: Mandated cross-sector reporting. Journal of Sociology \& Social Welfare, 34(3), 147-164.

McPhedran, S. (2009). Animal abuse, family violence, and child wellbeing: A review. Journal of Family Violence, 24, 41-52. doi: 10.1007/s10896-008-9206-3

Merzer, M., \& White, N. (2001, September 6). Nassau tourist icon burns. Miami Herald, pp. $1 \mathrm{~A} \& 2 \mathrm{~A}$.

Novak, B. J. (1999). Social work in the Bahamas: A profession helps to build a nation. International Social Work, 42, 117-126.
Rivett, M, \& Kelly, S. (2006). From awareness to practice: Children, domestic violence and child welfare. Child Abuse Review, 15(4), 224-242. doi: 10.1002/car.945

Rolle, B. M., \& Gibson, J. D. (2009). What's your duty? Customer duty \& investment digest of The Bahamas, 2009/2010. Nassau: Keepers.

Rolle, U. (2009). [Interview with Percy Grant, Bahamas Humane Society]. Unpublished raw data.

Royal Bahamas Police Force, Research \& Planning Unit. (2008a). [Data on homicide in the Bahamas]. Unpublished raw data.

Royal Bahamas Police Force, Research \& Planning Unit. (2008b). [Persons charged: entire Bahamas, 1991 to 2007]. Unpublished raw data.

Sherin, K. M., Sinacore, J. M., Li, X., Zitter, R. E., \& Shakil, A. (1998). HITS: A short domestic violence screening tool for use in a family practice setting. Family Medicine, 30(7), 508-12. Retrieved from

http://www.stfm.org/fmhub/FULLPDF/JULYA UG98/cram1.pdf

Simmons, C. A., \& Lehmann, P. (2007). Exploring the link between pet abuse and controlling behaviors in violent relationships. Journal of Interpersonal Violence, 22(9), 12111222. doi: 10.1177/0886260507303734

Smart, R. G., \& Patterson, S. D. (1990). Comparison of alcohol, tobacco, and illicit drug use among students and delinquents in the Bahamas. Bulletin of the Pan American Health Organization, 24(1), 39-45.

Smith, R. G. (2001, September 25). Vendors ready to trade again. The Tribune, p. 1.

Spencer, D. J. (1972). Suicide in the Bahamas. International Journal of Social Psychiatry, 18(2), 110-113. doi: 10.1177/002076407201800205

The Nature Conservancy, \& Bahamas National Trust. (2007). Results of the national voter survey on environmental issues, The Bahamas. Nassau: Author.

Thompson, K. L., \& Gullone, E. (2003). Promotion of empathy and prosocial behaviour 
in children through humane education.

Australian Psychologist, 38(3), 175-182. doi:

10.1080/00050060310001707187

United Nations Children's Fund. (2000).

Domestic violence against women and girls.

Innocenti Digest, 6. Retrieved from

http://www.unicef-

icdc.org/publications/pdf/digest6e.pdf

United Nations Office on Drugs and Crime, \& World Bank. (2007). Crime, violence, and development: Trends, costs, and policy options in the Caribbean. Washington, DC: World Bank. Retrieved from http://go.worldbank.org/HDBCAXW850

Women and domestic violence. (2006, February 1). [Editorial]. Nassau Guardian. Retrieved from http://archive.nassauguardian.net

World Health Organization (2008). Core health indicators: Per capita recorded alcohol consumption (litres of pure alcohol) among adults ( $>=15$ years). Retrieved from WHO Statistical Information System: http://www.who.int/whosis/database/core/core_ select_process.cfm?strISO3_select=ALL\&strIn dicator_select=AlcoholConsumption\&intYear_ select=latest $\&$ language $=$ english $\#$ 